\title{
All that glitters is not gold: Wages and education for US immigrants*
}

\author{
Simone Bertoli ${ }^{\mathrm{a}}$ and Steven Stillman ${ }^{\mathrm{b}}$ \\ ${ }^{\mathrm{a}}$ Université Clermont Auvergne, CNRS, IRD, CERDI and IZA ${ }^{\dagger}$ \\ ${ }^{\mathrm{b}}$ Free University of Bozen-Bolzano and IZA $A^{\ddagger}$
}

\begin{abstract}
Many destination countries consider implementing points-based migration systems as a way to improve migrants' quality, but our understanding of the actual effects of selective policies is limited. We use data from the ACS 2001-2017 to analyze the overlap in the wage distribution of low- and high-educated recent migrants from different origins after controlling for other observable characteristics. When we randomly match a highwith a low-educated immigrant from the same country, more than one-quarter of time the low-educated immigrant has a higher hourly wage, notwithstanding a statistically significant difference in the mean wage of the two groups for most origins. For 98 out of 114 countries, this synthetic measure of the overlap in the two wage distributions stands above the corresponding figure for natives. We also find that at least 82 percent of the variance in log wages for migrants with a given number of years of schooling is due to differences within rather than across countries. This suggests that heavily relying on education to select immigrants might fail to markedly improve their quality.
\end{abstract}

Keywords: migration; selection; wages; point-system; United States.

JEL classification codes: F22; J24.

*The Authors are grateful to the Guest Editor Cristina Tealdi and to two anonymous referees for their comments, and to George J. Borjas for sharing his code for identifying likely undocumented immigrants in US surveys; Simone Bertoli acknowledges the support received from the Agence Nationale de la Recherche of the French government through the program "Investissements d'avenir" (ANR-10-LABX-14-01) and from the Institut Universitaire de France; the usual disclaimers apply.

${ }^{\dagger}$ CERDI, Avenue Léon-Blum, 26, F-63000, Clermont-Fd; email: simone.bertoli@uca.fr.

${ }^{\ddagger}$ Department of Economics and Management, Piazza Università 1, Bozen-Bolzano, I-39100; email: steven.stillman@unibz.it 
"Remarkably little is known about [...] whether the chosen policy, in fact, has the desired outcomes in terms of the size and composition of the immigrant flow."

George J. Borjas, 2014, Immigration Economics, p. 215.

\section{Introduction}

Migrant-receiving countries are typically concerned with how well migrants perform in the local labor market and the extent to which their outcomes mirror those of similar natives. Policy makers and scholars usually rely on migrants' earnings at the destination as a synthetic measure of their quality. ${ }^{1}$ Evidence from a number of OECD countries that recent migrants' initial earnings have been declining over time (see, for instance, Borjas and Friedberg, 2009 and Aydemir and Skuterud, 2005 for the United States and Canada) has prompted debates in some of these countries around the need of reforming immigration policies with the goal of improving migrants' quality. In particular, there has been an increasing interest in instituting points-based systems that rely on a few socioeconomic characteristics, such as education, age and language proficiency, to select higher quality migrants. For instance, Borjas (1999) argued that "the United States could probably increase the skill level of its immigrant population by adopting a point system that relies on few socioeconomic characteristics-such as education, age and a measure of English proficiency." (p. 193). A number of countries, most prominently Canada and New Zealand, currently admit most migrants via points-based systems, however there has so far been little analysis examining whether these systems are capable of achieving their stated objectives, as the initial quote from Borjas (2014) suggests. One exception is Aydemir (2011), who finds that selective immigration policies have improved the observable skills of the migrants to Canada, but that migrants admitted for their skills do not perform better on the Canadian labor market.

It is prima facie intuitive that immigration policies that select individuals based on their observable characteristics, and most notably education, should be able to improve migrants' quality. ${ }^{2}$ However, the dispersion in wages across individuals also depend on a number of

1 "The broad interest in this subject is not surprising: the earnings that immigrants receive in destination countries and the evolution of their earnings paths are an important indicator not only of their own success and performance, but also of their overall contribution to the host countries' economies in terms of GDP growth and tax contributions." (Dustmann and Görlach, 2016, p. 1).

${ }^{2}$ Notice that non-points-based systems can be de facto selective, as policy-induced migration costs are typically more difficult to overcome for less educated potential migrants; for example, Bertoli et al. (2013) 
characteristics, such as innate ability, talent and attitude towards risk, that are not easily observable, ${ }^{3}$ and do not correlate perfectly with education (see, for instance, Heckman and Kautz, 2012). This is particularly true given that both across and within most developing countries there is substantial heterogeneity in the quality of the "same" amount of education. Borjas (1999) himself observes that differences in observable characteristics, such as age, education and occupation, explain only one third of the variation in earnings across workers on the US labor market, and this entails that a point-system "misses those intangibles that are the main determinants of what makes some workers successful and others unsuccessful." (p. 193).

The (strong) dependence of migrants' quality on characteristics that remain unobserved for migration officers does not just dilute the effectiveness of selective immigration policies in improving migrants' quality, but it could also produce perverse effects, as shown theoretically by Bertoli et al. (2016), who build on the seminal contribution by Borjas (1987). More specifically, when migrants are positively selected on unobservables, an increase in the selectivity of immigration policies that leaves the aggregate scale of migration unchanged leads to a reduction in the average quality of the high-educated immigrants, and to an increase in the average quality of low-educated immigrants, with a possible decline in migrants' quality. To put it differently, a greater emphasis on a narrow set of observable characteristics could end up discouraging talented and entrepreneurial-minded foreign-born workers without the required education credentials. The wages of these discouraged low-educated migrants can exceed those of the high-educated migrants that are induced to move by the scale-preserving increase in selectivity, thus reducing migrants' average wages at destination. ${ }^{4}$ Furthermore, as points-based systems generally treat educational qualifications identically regardless to

find that time-equivalent migration costs are two to three times lower for Ecuadorian migrants with a college degree relative to those with a high school education.

${ }^{3}$ The Canadian point systems goes beyond the narrow set of observable characteristics suggested by Borjas (1999), as it attributes up to 10 points (out of 100, with a pass mark of 67) to applicants with a full-time job offer of at least one year from a Canadian employer, and another 10 points for the adaptability of the applicant, which partly depends on his or her past work experience in Canada. This is true for the New Zealand point system as well

${ }^{4}$ Bertoli et al. (2016) demonstrate that the maximization of migrants' quality requires to equate the wages of the high-educated and low-educated migrants that are indifferent between migrating and staying, and this equalization occurs when the average wage of high-educated migrants exceeds the one of low-educated migrants, with this differential motivating the further increase in selectivity of immigration policies. 
the country in which they were earned, applicants from countries where the education systems are of poor quality could potentially crowd out applicants from countries with better human capital (Mattoo et al., 2008)..$^{5}$

We draw on data from the 2001-2017 rounds of the American Community Survey to analyze the origin-specific relationship between the wage distributions for low-educated (at most high-school dropouts) and high-educated (at least four years of college) immigrants in the US labor market. Our analysis consists of two complementary parts. First, we examine the difference in mean wages and the overlap in the wage distributions of these two groups of recent migrants with non-contiguous levels of education from 114 countries of origin after controlling for other observable characteristics through the estimation of a Mincer equation. As shown in Bertoli et al. (2016), the greater the overlap of the two distributions, the less likely that a point-system will markedly improve immigrants' quality. As noted above, this overlap can be caused by two factors: $(i)$ a greater intensity of selection on unobservables for low-educated versus high-educated migrants, ${ }^{6}$ or $(i i)$ because education is a poor measure of quality for certain migrants because of low quality education systems in their origin countries. In order to distinguish between these factors, our second analysis decomposes the variance of wages among recent migrants with the same level of education into within versus between country components. The larger the within country component, the more relevant that differential selection on unobservables is for explaining the overlap in the wage distribution between low- and high-educated workers.

We find that the difference in residual wages between the two groups is significantly positive for 95 out of 114 origin countries. However, when we randomly select one low-educated recent male migrant (at most a high school dropout), in 24.7 percent of the draws he has a wage that exceeds that for a randomly selected high-educated recent male migrant (with at least four years of college) from the same country of origin. ${ }^{7}$ This is mid-way between a situation in which education fully separates high-wage from low-wage individuals and a situation where education is uncorrelated with wages in the labor market at destination. There

\footnotetext{
${ }^{5}$ This can be partly limited by requiring applicants to provide an assessment of their foreign education credentials, as currently requested by Canada for its Federal skilled workers program.

${ }^{6}$ The intensity of selection is, as shown by Borjas (1987), an increasing function of migration costs, which are higher for uneducated than for educated potential migrants.

${ }^{7}$ This figure is obtained when weighting the origin-specific measure of overlap by the origin-specific number of immigrants in our sample; the unweighted average stands at 27.2 percent.
} 
are notable differences across the 114 countries included in our analysis, but for 98 of them, this synthetic measure of the overlap in the two distributions stands above the corresponding figure for US natives, which is equal to 13.8 percent. Interestingly, the percentage overlap for natives is less than what we would predict based of the difference in mean wages between the high- and low-educated natives using the relationship between the two observed for immigrants. This indicates that the wage distributions for immigrants, given the difference in means, have more overlap than that for natives.

We also find that most of the variance (at least 82 percent) in wages for migrants with a given number of years of schooling is due to differences in unobservables within rather than between countries. While education quality obviously varies across origin countries in our sample, a possible reason why low- and high-educated workers from the same country have similar wages is because the high-educated workers are less positively selected on unobservables than the low-educated workers.

These results are consistent with both de facto selectivity being stronger for low-educated migrants to the US and there being a large overlap in the wage distributions of low- and higheducated potential immigrants. Returning to the theoretical model in Bertoli et al. (2016), our findings suggest that a points-based system (or, more generally, a further increase in the selectivity on education) is unlikely to improve substantially the quality of migrants coming to the US.

Our empirical analysis is clearly contingent on how the destination labor market functions and on the pool of origins from which a country draws most of its immigrants. The residual wages that we obtain after estimating a Mincer equation reflect both individual unobserved characteristics and the returns to these characteristics at the destination. If high-educated foreign-born workers face more discrimination in the labor market against or have more difficulty accessing licensed occupations (Tani, 2018), this will also increase the extent to which the wage distributions for high- and low-educated immigrants overlap. ${ }^{8}$ However, it will also be true in this case that more intense selection on education would fail to improve immigrants' quality.

Our paper makes a unique contribution to the literature by focusing on a simple measure of whether education can serve as a good proxy for migrant quality and by distinguishing

\footnotetext{
${ }^{8}$ Consistent with this argument, we find that the overlap is lower for migrants originating from Englishspeaking countries where we expect less discrimination. However, the US receives the vast majority of their immigrants from other origins, notably in Latin America.
} 
the extent to which this is related to differential selection on unobservables versus differing quality of education systems across origin countries. Related papers have examined either the overall link between education and migrant outcomes (Aydemir, 2011) or the differences in returns to education across migrant origin countries (Mattoo et al., 2008), but not both in the same framework. Our analysis reveals that differences in unobservables between low- and high-educated migrants are strong enough such that residual wages for a substantial share of high-educated immigrants are lower than those for low-educated migrants even though the difference in means for the two groups is large and significant. Thus, we go beyond previous papers that show low or non-significant return to foreign education.

The rest of the paper is structured as follows: in Section 2, we introduce the data used in our analysis and discuss some key definitions. In Section 3, we present our empirical approach and main findings. Section 4 explores the heterogeneity in the results obtained from the empirical analysis, and discusses some relevant robustness checks. Finally, Section 5 draws the main conclusions.

\section{The ACS data}

Our analysis uses data from the 2001-2017 rounds of the American Community Survey. Importantly, the ACS provides detailed information on the level of education of each respondent, on total pre-tax wage and salary income, as well as on the country of birth and on the years since migration for foreign-born individuals in the sample. It also provides large sample sizes from a large range of origin countries which is important for our analysis.

We restrict our sample to foreign-born men aged 25 to 64 living outside group quarters at the time of the interview, but excluding US citizens born abroad. The focus on prime-age men is meant to avoid having to model selection into employment. We also restrict our sample to migrants $(i)$ who arrived in United States between 2 and 10 years before the survey, ${ }^{9}$ and (ii) were at least 25 years-old at the time of immigration. The first restriction is made so that our findings reflect differences in migrant quality and not differential assimilation for

\footnotetext{
${ }^{9}$ The insights from our empirical analysis remain unchanged if we focus on immigrants who arrived either 2 to 5 or 2 to 20 years before the survey; results are available from the Authors upon request. This suggests that assimilation profiles that vary by education and/or country of birth are not important for explaining how wages vary by observed education. As we discuss further below, this is also the case when we directly allow assimilation profiles to vary by country of birth.
} 
low- versus high-educated workers, ${ }^{10}$ as well as to avoid that the longer time required to ensure the transferability of the human capital of high-educated workers, who might hold low-paying occupation right after immigration artificially magnifying the overlap between the two wage distributions. The second restriction is made to ensure that all individual in our sample are likely to have completed their education abroad (Beine et al., 2007). ${ }^{11}$ These restrictions give us a sample of 571,746 male migrants originating from 144 distinct countries of origin.

Labor earnings are deflated using the CPI-U series (June), ${ }^{12}$ that we then use to compute real hourly wages using information on the number of weeks worked over the 12-month recall period, and on the number of hours worked per week. ${ }^{13,14}$ The income data in the ACS is either self-reported by the respondent or imputed by the Census Bureau. As pointed out by Borjas (2014), income is imputed for a large and increasing share of foreign-born individuals. ${ }^{15}$ The imputation process is a hot-deck procedure and does not consider immigrant status, so that natives, which are likely to have higher wages, are over-represented among the donors that provide income data for immigrants with missing wage information. Hence, the wage gap between migrants and the native-born will be understated among those with imputed incomes. However, since our focus is on the relative wages between low- and higheducated migrants from the same origin country, this procedure should have little impact on our results unless its frequency differs between low- and high-educated migrants. As the Census Bureau provides flags to identify individuals with imputed rather than observed

\footnotetext{
${ }^{10}$ We further examine this issue by allowing for returns to education to vary with time in the US.

${ }^{11}$ The ACS does not provide information on the country in which the highest degree of education of a respondent was acquired, so we cannot verify whether this threshold is effective in excluding foreign-born immigrants who received some of their education in the US; however, our results are robust to increasing this threshold to 30 years and to excluding from the group of high-educate immigrants individuals with more than four years of college (as individuals aged 25 and above at immigration might have completed their post-graduate education in the US).

${ }^{12}$ Source: https://www.bls.gov/cpi/tables/supplemental-files/home.htm (Accessed: December 4, 2018).

${ }^{13}$ Our sample of immigrants includes both waged workers and self-employed individuals, but the share of this second group is small $(39,185$ individuals out of 571,746$)$; the choice to include, as we do, or to exclude them from the analysis sample has no impact on our findings.

${ }^{14}$ We exclude observations with a real wage below USD 4 or above USD 150 per hour.

${ }^{15}$ Borjas (2014) reveals that 29.2 percent of the immigrants arrived to the US in the last five years in the ACS 2009-2011 have missing data on labor earnings (see p. 60), with foreign-born workers with imputed wage observations having weekly wages that are 7.1 percent higher than those of foreign-born workers with self-reported, i.e., non-imputed, wage observations.
} 
income data, we can also test whether our results are robust to excluding these individuals.

Our main analysis focuses on two distinct and non-contiguous groups defined on the basis of their level of education: migrants with at least four years of college (high-educated) and migrants who have not finished high-school (low-educated). This ensures that the difference in years of schooling between any high- and low-educated migrant is at least equal to five years. We restrict our main analysis to 114 out of the 144 countries in the sample where we have at least 50 observations referring to male immigrants that are either high- or low-educated. The total number of high- or low-educated male migrants from these origin countries stands at 155,643 .

\section{Empirical analysis}

We describe here $(i)$ the specification of the Mincerian regression that is used to adjust the log real hourly wages for differences in observable characteristics other than education and country of birth, (ii) the extent of the overlap in the wage distributions for high- and low-educated immigrants, and (iii) our variance decomposition analysis.

\subsection{Mincerian regression and adjusted wages}

The goal of our analysis is to examine the relationship between education levels and migrant quality, holding all else equal; thus, we begin by using a simple Mincerian regression to generate a measure of each migrant's wage controlling for other observable characteristics. Specifically, we estimate the following regression on the full sample of male migrants: ${ }^{16}$

$$
\ln w_{i}=\boldsymbol{\alpha}^{\prime} \boldsymbol{x}_{i}+\beta s_{i}+d_{i}^{y}+d_{i}^{r}+d_{i}^{j}+\epsilon_{i}
$$

where $\ln w_{i}$ is the logarithm of the real hourly wage of individual $i, \boldsymbol{x}_{i}$ is a vector of individual characteristics including a polynomial in age and years since immigration, a dummy for married individuals, and the number (total and under 5 years) of children, $s_{i}$ is the number of completed years of schooling of individual $i$, and $d_{i}^{y}, d_{i}^{r}$, and $d_{i}^{j}$ are respectively dummies for the year in which individual $i$ was interviewed, for the census region of residence in the US

\footnotetext{
${ }^{16}$ The results of our analysis are unaffected if we restrict the sample to just low- and high-educated migrants as defined above before estimating the Mincer regression, but the smaller sample size would reduce the precision of the estimated coefficients; results are available from the Authors upon request.
} 


\section{Table 1: Mincer regressions}

Dependent variable: $\ln w_{i}$

\begin{tabular}{|c|c|c|c|}
\hline & $(1)$ & $(2)$ & $(3)$ \\
\hline \multirow[t]{2}{*}{ Age } & $0.049 * * *$ & $0.047^{* * *}$ & $0.065^{* * *}$ \\
\hline & {$[0.002]$} & {$[0.002]$} & {$[0.002]$} \\
\hline \multirow[t]{2}{*}{ Age, squared } & $-0.001^{* * *}$ & $-0.001^{* * *}$ & $-0.001^{* * *}$ \\
\hline & {$[0.00002]$} & {$[0.00002]$} & {$[0.00002]$} \\
\hline \multirow[t]{2}{*}{ Years since migration } & $0.027 * * *$ & $0.034^{* * *}$ & $0.030^{* * *}$ \\
\hline & {$[0.001]$} & {$[0.001]$} & {$[0.001]$} \\
\hline \multirow[t]{2}{*}{ Years since migration, squared } & $-0.0003^{* * *}$ & $-0.0004^{* * *}$ & $-0.0004^{* * *}$ \\
\hline & {$[0.00002]$} & {$[0.00002]$} & {$[0.00002]$} \\
\hline \multirow[t]{2}{*}{ Years of education } & $0.056^{* * *}$ & $0.064^{* * *}$ & $0.068^{* * *}$ \\
\hline & {$[0.0004]$} & {$[0.0004]$} & {$[0.0005]$} \\
\hline \multirow[t]{2}{*}{ Married } & $0.096^{* * *}$ & $0.109^{* * *}$ & $0.091^{* * *}$ \\
\hline & {$[0.004]$} & {$[0.004]$} & {$[0.005]$} \\
\hline \multirow[t]{2}{*}{ Number of children } & $0.008^{* * *}$ & $0.008^{* * *}$ & $0.005^{* * *}$ \\
\hline & {$[0.001]$} & {$[0.001]$} & {$[0.002]$} \\
\hline \multirow[t]{2}{*}{ Number of children below 5} & $0.044^{* * *}$ & $0.055^{* * *}$ & $0.036^{* * *}$ \\
\hline & {$[0.003]$} & {$[0.003]$} & {$[0.004]$} \\
\hline Dummies for survey year & Yes & Yes & Yes \\
\hline Dummies for country of birth & Yes & Yes & Yes \\
\hline Dummies for census region & Yes & Yes & Yes \\
\hline Observations & 571,746 & 453,994 & 363,551 \\
\hline Adjusted- $R^{2}$ & 0.271 & 0.323 & 0.236 \\
\hline \multicolumn{4}{|c|}{$\begin{array}{l}\text { Notes: }{ }^{*},{ }^{* *} \text { and }{ }^{* * *} \text { denote significance at the } 10,5 \text { and } 1 \text { percent level } \\
\text { respectively; Column (1) includes all male immigrants from } 144 \text { distinct }\end{array}$} \\
\hline \multicolumn{4}{|c|}{ countries of birth; Column (2) only uses observations with non-imputed } \\
\hline \multirow{3}{*}{\multicolumn{4}{|c|}{$\begin{array}{l}\text { wage observations; Column (3) only uses observations referring to likely } \\
\text { documented migrants; } \ln w_{i} \text { is the logarithm of the real hourly wage of } \\
\text { individual } i \text {; observations are weighted using sampling weights. }\end{array}$}} \\
\hline & & & \\
\hline & & & \\
\hline \multicolumn{4}{|c|}{ Source: Authors' elaboration on ACS 2001-2017. } \\
\hline
\end{tabular}

and for the country of birth. Eq. (1) assumes that the return to schooling $\beta$ does not vary across origins; relaxing this assumption and allowing $\beta$ to vary across countries of birth only marginally improves the goodness of fit of the Mincerian regression. Eq. (1) also assumes that returns to education do not vary with years in the US; while we find strong evidence that 
returns do increase with time in the US, our main results are unaffected by changing to this more flexible specification. Our results are also unaffected by allowing for semi-parametric wage-age and assimilation profiles (by including dummy variables for all possible values) and by allowing all parameters in the wage equation to vary by region of birth; results are available from the Authors upon request. Overall, these robustness checks clearly show that neither differences by country of origin in returns to education nor in assimilation profiles are important for explaining the across-country variance of wages of workers with the same level of education.

Using the estimates from Eq. (1), that are reported in the first data column of Table 1, we get rid of differences in real hourly wages across individuals that are due to all observable individual characteristics except education and country of birth. We denote the log of the real hourly wage adjusted for differences in observable characteristics as $\ln \widehat{w}_{i}$; formally, $\ln \widehat{w}_{i} \equiv \ln w_{i}-\widehat{\boldsymbol{\alpha}}^{\prime} \boldsymbol{x}_{i}-\widehat{d}_{i}^{y}-\widehat{d}_{i}^{r}$, and we compute the adjusted wage of a 30 year-old immigrant who arrived in the US five years before the survey, who is not married and who does not have children.

\subsection{Overlap in the wage distributions}

We now examine the degree of overlap between the wage distributions of low- and higheducated migrants from each of the 114 countries for which we have at least 50 migrants satisfying our sample selection criteria and who are either low- or high-educated. We begin by illustrating our findings with examples from the two largest origin countries for US migrants, Mexico and India. ${ }^{17}$ The average (adjusted) wage of a high-educated Indian immigrant is 116.4 percent higher than the average wage of a low-educated Indian immigrant, while the corresponding difference for Mexico around half at 59.0 percent, and the two differences are significant at conventional confidence levels. Figures 1 and 2 report the (smoothed) distributions of adjusted real log hourly wages for high- and low-educated migrants from India and Mexico, respectively. The two figures reveal a remarkably different variance in the

\footnotetext{
${ }^{17} \mathrm{~A}$ large body of literature has analyzed the prevailing pattern of selection of Mexican migrants to the United States; the negative selection hypothesis put forward by Borjas (1987) has been only partly validated, with Chiquiar and Hanson (2005) providing evidence of intermediate selection, McKenzie et al. (2010) providing evidence of more positive selection out of communities with limited networks at destination, and Fernández-Huertas Moraga (2013) evidencing a positive selection out of rural areas.
} 
(log) wages of high-educated Indian and Mexican immigrants, as well as a markedly larger overlap between the two distributions for migrants coming from Mexico than from those coming from India. ${ }^{18}$

Figure 1: Adjusted log real wage distributions for high- and low-educated migrants (India)

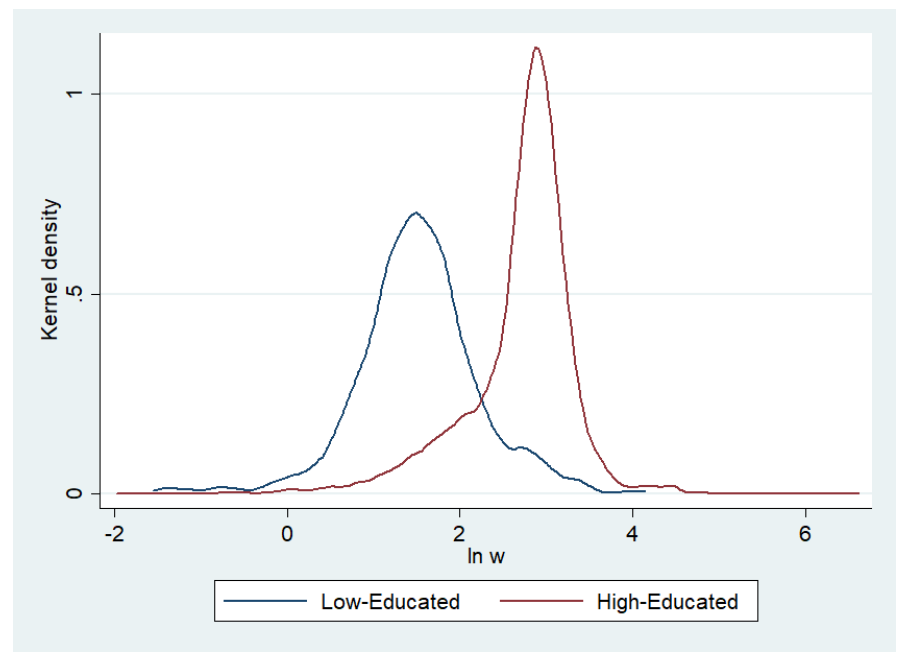

Notes: the two smoothed distributions are based on a sample of 20,293 Indian migrants to the US; the log real wage is adjusted for differences in individual observable characteristics except those due to schooling. Source: Authors' elaboration on ACS 2001-2017.

We next formalize our measured of the extent of the overlap in the wage distributions of high- and low-educated migrants. Let $\ln \widehat{w}_{i j}^{e}$ represent the adjusted log hourly real wage for an immigrant $i$ born in country $j$ which is either high-educated, i.e., $e=h$, or low-educated, i.e., $e=l$. We define as $\mu_{j}$ the average difference between $\ln \widehat{w}_{i j}^{h}$ and $\ln \widehat{w}_{i j}^{l}{ }^{19}$ Similarly, we define $p_{j}$ as the share of randomly drawn pairs composed by a high-educated and by a low-educated immigrant born in country $j$ such that $\ln \widehat{w}_{i j}^{h}<\ln \widehat{w}_{i j}^{l}$. More specifically, we partition the distribution of the adjusted log hourly real wage for high-educated immigrants from each

\footnotetext{
${ }^{18}$ This could reflect differences in the distribution across occupations of immigrants from these two countries (that are also correlated with differences in the field of study of tertiary educated immigrants), as well as the larger fraction of Indian immigrants that are admitted to the United States through selective entry channels such as the H1-B visa program.

${ }^{19}$ Notice that this is not a measure of the causal effect of education on the wage incomes on the US labor market for the immigrants from country $j$, as it also reflects possibly differences in the pattern or in the intensity of self-selection on unobservables between high- and low-educated immigrants.
} 
Figure 2: Adjusted log real wage distributions for high- and low-educated migrants (Mexico)

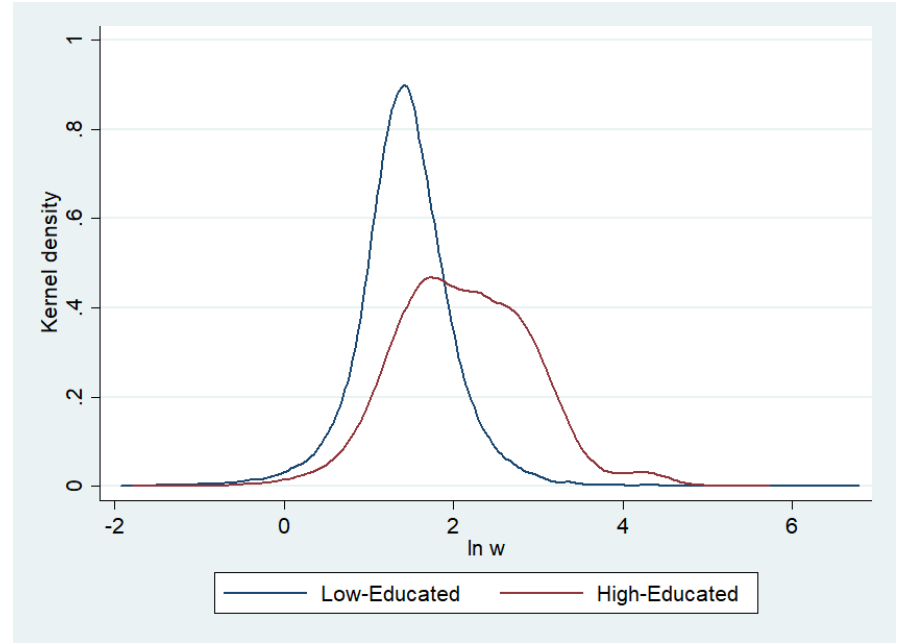

Notes: the two smoothed distributions are based on a sample of 27,959 Mexican migrants to the US; the log real wage is adjusted for differences in individual observable characteristics except those due to schooling. Source: Authors' elaboration on ACS 2001-2017.

country $j$ into 1,000 quantiles, and we then compute for each low-educated immigrant from the same country $j$ the quantile to which he or she belongs to; the average value across low-educated immigrants of the high-educated immigrants with lower wages represents our measure of overlap $p_{j}$. If there is no overlap in the two distributions (and if $\mu_{j} \geq 0$ ), then $p_{j}=0$, while $p_{j}=0.5$ if there is a perfect overlap between the two distributions. ${ }^{20}$

The proposed measure of the extent of the overlap in the wage distributions for highand low-educated migrants stands at 10.3 percent for India and 26.8 percent for Mexico, consistent with the visual impressions conveyed by Figures 1 and 2. While the partition of the sample of Indian migrants into two groups of education also results in a rather clear separation in terms of the wages earned on the US labor market, the same does not occur for Mexico. When we randomly match a Mexican migrant who is, at most, a high-school dropout with a migrant from the same country with at least four years of college, there is a 26.8 percent probability that the real hourly wage of the former exceeds the one of the latter,

\footnotetext{
${ }^{20} \mathrm{~A}$ possible theoretical measure of the extent of overlap between two distributions with probability density function represented by $f(x)$ and $g(x)$ is given by the (squared) Hellinger distance $H[f(x), g(x)]$, which is defined as $H^{2}[f(x), g(x)]=1-\int_{-\infty}^{+\infty} \sqrt{f(x) g(x)} \mathrm{d} x$; clearly, if $H[f(x), g(x)]=0$, then the probability that a realization drawn from $f(x)$ is higher than a realization drawn from $g(x)$ is 50 percent.
} 
even though the difference between the means of the two groups is positive and significant.

Table 2 shows the distribution of $p_{j}$ across all countries of origin as well as the distribution across all migrants (e.g., where each country is weighted by the number of migrants in our sample). The mean and median value of $p_{j}$ across all countries of origin stands at 27.20 and 28.41 percent, respectively, revealing that the value of $p_{j}$ for Mexico is hardly an exception. The numbers are also quite similar, a mean of 24.7 percent and median of 26.8 percent when accounting for the different number of migrants in the US form different origin countries.

Table 2: The distribution of overlap in wages between high- and low-educated migrants

\begin{tabular}{lcc} 
& $\begin{array}{c}\text { Across } \\
\text { origin countries }\end{array}$ & $\begin{array}{c}\text { Across } \\
\text { recent migrants }\end{array}$ \\
\hline Mean & 27.20 & 24.70 \\
Std. Dev. & 10.13 & 9.17 \\
$10^{\text {th }}$ Percentile & 13.15 & 10.30 \\
$25^{\text {th }}$ Percentile & 20.22 & 13.70 \\
$50^{\text {th }}$ Percentile & 28.41 & 26.77 \\
$75^{\text {th }}$ Percentile & 33.67 & 30.58 \\
$90^{\text {th }}$ Percentile & 37.27 & 37.41 \\
\hline Sample Size & 114 & 155,643 \\
Notes: The second column is weighted by the total \\
number of recent low- and high-educated migrants \\
in the US from each origin country; see the text for \\
more detail.
\end{tabular}

Source: Authors' elaboration on ACS 2001-2017.

As a reference point, we compute the same measure of overlap also for US natives. ${ }^{21}$ For 98 out of the 114 countries included in our analysis, our measure $p_{j}$ of the overlap of the two distributions exceeds that for US natives. Similar, this is true for nearly 75 percent of

\footnotetext{
${ }^{21}$ In order to do so, we estimated the Mincerian equation on a sample of 1,194,743 male natives from the ACS 2001-2017 aged 25 to 64 and with no more than 10 years of potential labor market experience, regressing the log real hourly wage on a quadratic function of potential labor market experience, on martial status, on the total and below five number of children, and on the number of completed years of schooling, including also dummies for the year of the survey and for the census regions of residence. The value of the overlap $p_{U S}$ between the two distributions of adjusted wages stands at 13.8 percent, while $\mu_{U S}$ is equal to 98.0 percent.
} 
migrants in our sample. For the top 10 percent of countries, there is an almost perfect overlap in the two distributions (the $90^{t h}$ percentile across countries is 37.3 percent). Overall, there is strong evidence that for most immigrants education is not a strong predictor of success on the US labor market. This, in turn, indicates that conferring a pivotal role to education in the selection of migrants might fail to induce a substantial increase in their average quality, and it might even potentially backfire, as suggested by Bertoli et al. (2016).

Figure 3: Overlap in the distributions and return to education

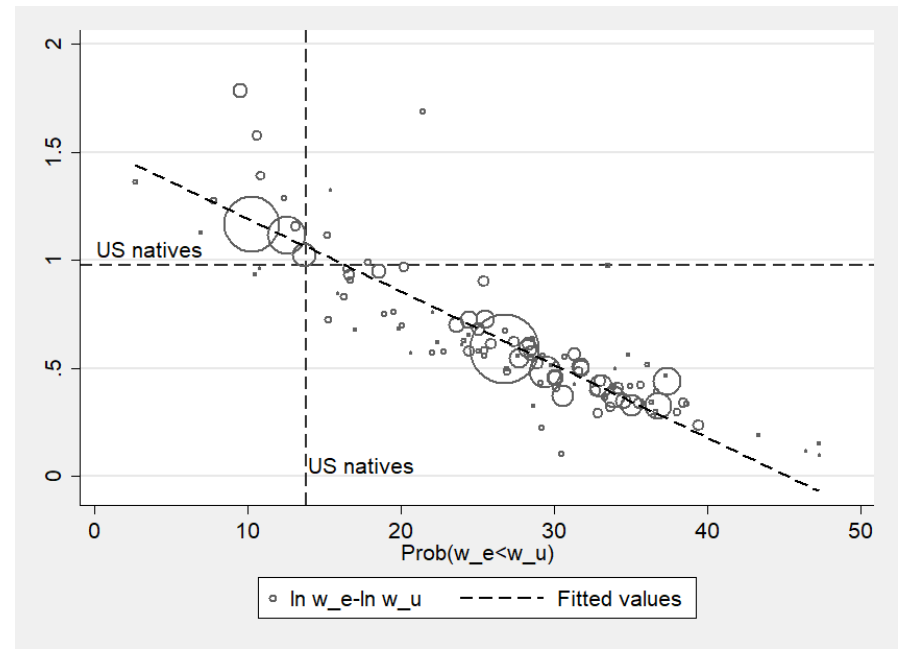

Notes: the figure plots the values of $\mu_{j}$ and $p_{j}$ for each country of birth; the size of each bubble is proportional to the number of observations in the ACS 2001-2017 (high- and low-educated immigrants) for each country; the fitted line comes from a weighted linear regression of $\mu_{j}$ and $p_{j}$, with weights equal to the origin-specific number of observations in the ACS 2001-2017.

Source: Authors' elaboration on ACS 2001-2017.

The overlap, that we measure through $p_{j}$, is a function of $(i)$ the difference in the expected value of wages for high- and low-educated immigrants, i.e., $\mu_{j}$, and $(i i)$ the dispersion in wages within each of the two groups. Figure 3 plots $p_{j}$ against $\mu_{j}$ : there is a clear negative relationship between the two. When we regress the overlap $p_{j}$ on $\mu_{j}$, the latter explain 73.9 percent of the variability in the former and this share increases to 81.8 percent when we also add a squared term for $\mu_{j}$. When we compute the Spearman's rank correlation coefficient between the ranking of the 114 origin countries in our sample with respect to $p_{j}$ and with respect to (minus) $\mu_{j}$ we obtain a value at 0.903 , signaling that the two rankings are indeed very similar. 
However, what is interesting is not only the (negative) relationship between $p_{j}$ and $\mu_{j}$, but the high value of the former even when the latter is large and significant. Origin countries whose high-educated migrants earn on average around 50 percent more than low-educated migrants have a value of $p_{j}$ of around 30 percent, so that a substantial overlap in the two distributions does not require a return to education on the US labor market that is close to zero. A one-sided $t$-test does not reject at the 5 percent confidence level the null hypothesis that $\ln \widehat{w}_{j}^{h}-\ln \widehat{w}_{j}^{l}=0$ against the alternative that $\ln \widehat{w}_{j}^{h}-\ln \widehat{w}_{j}^{l}>0$ for just 19 out of 114 origin countries.

Overall, these results show that a substantial difference in the average wages of high- and low-educated migrants, which is often used to motivate an increasing reliance on education to select immigrants, can occur at the same time as a large overlap in the distributions of wages for these workers, which can cause an increase in selectivity to have detrimental effects on migrants' quality. It is worth noting that the countries of origin that have high wage levels and little overlap in the wage distribution are mostly those with few low-educated migrants in the US (including large source countries such as India and China). The majority of these migrants are in the US on employer-sponsored visas, which are likely more effective in screening potential immigrants on the basis of attributes that go beyond education.

Furthermore, if we use the estimated relationship between $p_{j}$ and $\mu_{j}$ from the sample of 114 countries to predict, given the difference in mean wages for native workers, the overlap for natives, we obtain a value that is substantially above the actual value of 13.8 percent. Specifically, we obtain a predicted value of 16.6 percent when regressing $p_{j}$ on $\mu_{j}$ and $\mu_{j}^{2}$ and 18.2 percent when dropping the squared term. This, in turn, suggests that the overlap of the two wage distributions for immigrants is larger (given $\mu_{j}$ ) than the corresponding overlap for native workers.

\subsection{Variance decomposition}

We next decompose the variance of migrants' log wages at each level of education into withinand between-country components. This allows us to examine the extent to which differences in the quality of origin country education is responsible for the weak relationship between education and wages for migrants. We do this by pooling the adjusted log real wages of all migrants together and then decomposing the variance of the wages separately for migrants with a different number of years of education. This is done as well for "medium" educated 
migrants, i.e., high-school dropouts and individuals with some college, who are not included in our prior analysis. The variance of the adjusted log real wages $\ln \widehat{w}_{i}$ increases for migrants with a higher level of education, consistently with Chen (2008), as unobservable individual characteristics, such as ability, are likely to influence more the productivity of high-educated individuals. The results from this exercise are presented in Figure 4.

Figure 4: Share of the variance in adjusted log wages due to differences across countries

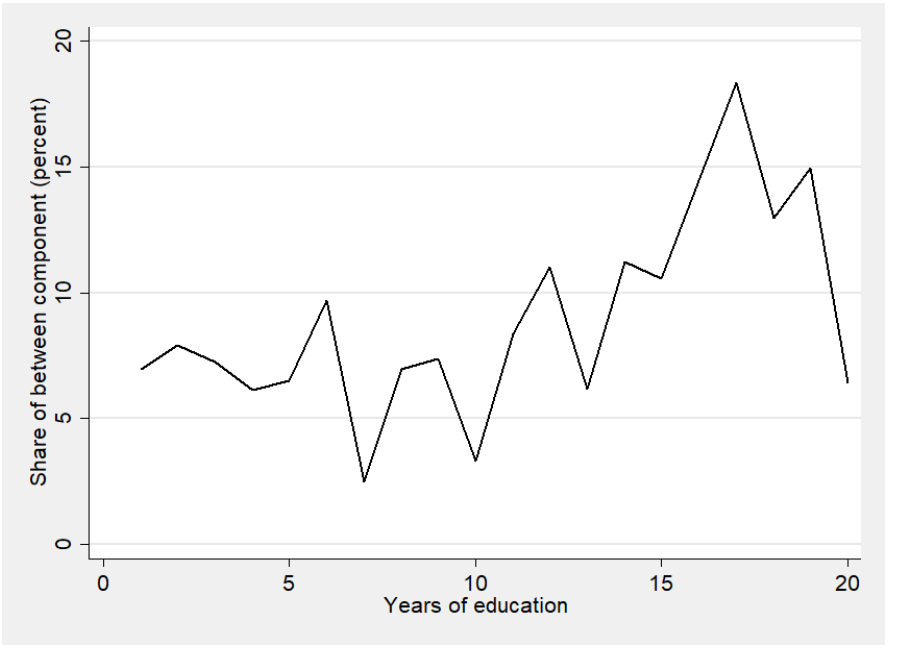

Notes: the figure reports the share of the total variance in adjusted log hourly real wages for immigrants with a different number of years of schooling that is due to differences across countries.

Source: Authors' elaboration on ACS 2001-2017.

This decomposition reveals two main facts: First, the share of the between component in the total variance is highest for high-educated migrants, consistently with the idea that there is a heterogeneity in the real content of nominally equivalent levels of education (Mattoo et al., 2008). Second, the between component explains, at most, 18 percent of the total variance in adjusted log wages. Most of the variance is due to differences in unobservables within origins. This provides strong evidence that, while education quality varies across origin countries in our sample, the principle reason why low- and high-educated workers from the same country have similar wages is because the high-educated workers are less positively selected on unobservables than the low-educated workers. 


\section{Further empirical analyses}

We explore here the some relevant dimensions of heterogeneity in the results obtained from our empirical analysis, and we also present some important robustness checks.

\subsection{Heterogeneous effects}

We consider three dimensions along which our results could be heterogeneous: $(i)$ language spoken at origin, $(i i)$ length of the migration experience, and ( $i i i)$ year of the survey.

\subsubsection{English-speaking countries}

High-educated immigrants from English-speaking origin countries could be better able to transfer the various (observed and unobserved) facets of their human capital to the US labor market, thus reducing the extent of the overlap in the two (adjusted) wage distributions. We rely on data from Mayer and Zignago (2011) to identify the 29 origin countries that have English as an official language. The mean value of the overlap for the English-speaking countries of origin stands at 25.22 percent across countries (19.81 percent when weighting by the number of immigrants). ${ }^{22}$ The measured overlap is higher than the corresponding value for natives for 22 out of 29 countries and the wage difference between high and low-educated immigrants is insignificant for only 5 out of 29 origin countries. For the 85 non-Englishspeaking countries, the mean value of the overlap stands at 27.87 percent across countries (26.89 percent when weighting by the number of immigrants). The measured overlap is higher than the corresponding value for the natives for 76 out of 85 countries and the wage difference between high and low-educated immigrants is not significant for 14 out of 85 origin countries. Thus, the overlap is indeed lower for English-speaking origin countries, but this is still substantially larger than the one that we observe for natives.

\subsubsection{Length of the migration experience}

Our analysis considers immigrants who have arrived between 2 and 10 years before the year of the survey. However, for a given cohort of immigrants, the measure of overlap could

\footnotetext{
${ }^{22}$ The large difference between the weighted and the unweighted average reflects the fact that the former is mostly driven by India, as Indian immigrants represent a large share of immigrants to the US from English-speaking countries.
} 
vary with the time elapsed since migration. In order to test whether this is the case, we have re-run the analysis separately for immigrants with 6 to 10 years since migration. For this sub-sample, the measured overlap stands at 25.57 percent across countries, slightly below the 27.21 percent that we obtain when using immigrants with 2 to 10 years since migration. ${ }^{23}$ Thus, these results suggests that the extent of overlap between the (adjusted) wage distributions for high- and low-educated immigrants is partly reduced over time, but it is far from vanishing at least up to 10 years.

\subsubsection{Evolution of the US labor market}

The US labor market has experienced substantial changes over the period covered by our analysis (2001 to 2017), with an increase in the relative demand for high-educated workers, partly because of technological factors and increasing exposure to trade with developing countries (Autor and Dorn, 2013; Autor et al., 2013). Has this contributed to reduce the extent of the overlap of the wage distributions for foreign-born workers? We can split the sample into two sub-periods (2001 to 2008 and 2009 to 2017), to see whether there any systematic tendency in the measure of overlap.

When using the ACS 2001-2008, we obtain a measure of overlap that stands at 28.87 percent across countries (26.82 percent when weighting by the number of immigrants). The corresponding figures when using the ACS 2009-2017 stands at 26.00 percent (22.80 percent when weighting by the number of immigrants). Thus, the measure of overlap, which reflects the evolution of the labor market at destination, has gone down slightly over time. However, our main results hold in the recent years of the sample where the impact of trade with China has been the largest.

\subsection{Robustness checks}

We consider here whether our results are robust to dropping observations $(i)$ where labor earnings have been imputed, and (ii) that correspond to likely undocumented immigrants, and when we (iii) modify the boundaries of the group of low-educated immigrants.

\footnotetext{
${ }^{23}$ The corresponding weighted figure stands at 23.85 percent, compared to 24.73 percent obtained in the full sample.
} 


\subsubsection{Imputed wages}

As discussed above in Section 2, one concern with using ACS data to examine wages for migrants is the high incidence of observations with non-reported wage figures, which are imputed. Imputation introduces a specific form of measurement error in the data. In our analysis data, there is a substantially larger share of imputed income observations for loweducated migrants (32.0 percent) than for high-educated migrants (12.2 percent). Hence, it is possible that this differential incidence of imputed wages artificially magnifies the extent of the overlap in the two distributions, as immigrants with missing wage data are assigned observations originating mostly from (similar) natives. In order to deal with this concern, we repeat the analysis on the sub-sample of male immigrants with non-imputed total pre-tax wage and salary income. The estimates of the Mincer regression on this restricted sample are reported in the second data column in Table 1: the return to one additional year of schooling increases from 0.056 to $0.064 \mathrm{log}$ points, and the adjusted $R^{2}$ of the model also increases from 0.271 to 0.323 . Removing the noise introduced by the hot-deck imputation for wages also increases the return from each additional year of experience on the US labor market from 0.027 to 0.034 log points. With the estimates from the restricted sample used in Column (2) in Table 1, we obtain that the average measure of the extent of the overlap in the distributions of wages for high- and low-educated migrants is reduced from 27.2 to 25.0 percent, still more than 1.8 times the corresponding figure for US natives. For Mexico, the exclusion of observations with imputed wages reduces the value of $p_{j}$ from 26.8 to 23.5 percent, ${ }^{24}$ while the corresponding reduction for India is proportionally larger, from 10.3 to 8.3 percent.

\subsubsection{Likely undocumented status of the immigrants}

A second concern is that wages may be artificially low for undocumented migrants because of their inability to receive the full return to their human capital (see Ortega and Hsin, 2018 for evidence on the substantial size of the wage penalty for undocumented immigrants on the US labor market). Undocumented migrants are predominantly low-educated but the wage penalty for being undocumented on the US labor market is likely to be larger for higheducated immigrants, so that it is a priori unclear how this should influence the measured

\footnotetext{
${ }^{24}$ For Mexico, 8,670 out of 31,945 observations referring to either low- or high-educated individuals have imputed wage observations, i.e., 27.1 percent of the original sample.
} 
extent of overlap between the two distributions. To examine whether this is an issue in our analysis, we follow Borjas (2017) to identify likely undocumented immigrants in the ACS, ${ }^{25}$ and then exclude these individuals from our analysis. ${ }^{26}$ Doing so has little impact on our results as the average value of $p_{j}$ over the 114 countries of origin now increases from 27.2 to 28.8 percent.

\subsubsection{Definition of the group of low-educated immigrants}

A third concern resides in our definition of the group of low-educated immigrants, which does not include high-school graduates. These represent a substantial share of recent male immigrants to the US for a large number of countries of origin. Including high-school graduates in the group of low-educated individuals reduces the distance between the two non-contiguous group of immigrants from at least five to at least four years of schooling, and it should thus increase the extent of the overlap in the two distributions. ${ }^{27}$ The average value of $p_{j}$ only marginally increases, from 27.2 to 29.3 percent. This, in turn, demonstrates that our synthetic measure of overlap is not particularly sensitive to our restrictive definition of the group of low-educated immigrants.

\section{Concluding remarks}

In this paper, we use data from the 2001-2017 rounds of the American Community Survey to evaluate the extent to which a point-system that mainly relies on education to select migrants is able to attract higher quality migrants in the US context. Our analysis consists of two complementary parts. First, we examine the overlap in the wage distribution of low

\footnotetext{
${ }^{25}$ Borjas (2017) identifies a foreign-born as a (likely) documented immigrant if at least one of these conditions is satisfied: (a) that person arrived before 1980; $(b)$ that person is a citizen; $(c)$ that person receives Social Security benefits, SSI, Medicaid, Medicare, or Military Insurance; $(d)$ that person is a veteran, or is currently in the Armed Forces; $(e)$ that person works in the government sector; $(f)$ that person resides in public housing or receives rental subsidies, or that person is a spouse of someone who resides in public housing or receives rental subsidies; $(g)$ that person was born in Cuba; $(h)$ that person's occupation requires some form of licensing; ( $i$ ) that person's spouse is a legal immigrant or citizen.

${ }^{26}$ The results of the estimation of the Mincerian regression on the restricted sample of likely documented foreign-born are reported in the third data column of Table 1.

${ }^{27}$ Once we do so, the total number of low-educated recent male immigrants included in the analysis almost doubles, from 41,278 to 82,321 .
} 
and high educated recent migrants from different countries of origin after controlling for other observable characteristics. Second, we decompose the variance of wages among recent migrants into within versus between country components.

While superficially a migration system that selects individuals based on their skills should be able to select more skilled individuals, as shown by Bertoli et al. (2016), these systems also influence the prevailing pattern of selection on unobservables and this indirect effect can be strong enough to counter the direct effect due to selection on observables embedded in the policy. Furthermore, as points-based systems generally treat educational qualifications identically regardless to the country in which they were earned, applicants from countries with a poor quality of human capital could potential crowd out applicants from countries with a better level of human capital (Mattoo et al., 2008).

We find that, if we randomly select one low-educated recent migrant (at most a highschool dropout), in 24.7 percent of the cases they have a wage that exceeds that for a randomly selected high-educated recent migrant (with at least four years of college) from the same country of origin. This is mid-way between a situation in which education fully separates high-wage from low-wage individuals (a measure of overlap equal to 0 percent) and a situation where education is uncorrelated with wages (50 percent). We also find that most of the variance (at least 82 percent) in wages for migrants with a given number of years of schooling is due to differences in unobservables within rather than between countries.

Our paper makes a unique contribution to the literature by focusing on a simple measure of whether education can serve as a good proxy for migrant quality and by distinguishing the extent to which this is related to differential selection on unobservables versus differing quality of education systems across origin countries. Returning to the theoretical model in Bertoli et al. (2016), our results suggest that a simple points-based system, such as the one put forward by Borjas (1999), is unlikely to improve substantially the quality of migrants coming to the US. The same also applies if the wages at destination of high-educated immigrants are depressed because of institutional factors, such as licensing or pure discrimination, as selecting on the basis of education credentials makes limited sense if these are poorly rewarded on the labor market at destination. Alternatively, it is possible that a more developed employer-based migration system, such as the one used in Australia, might be better able to correctly weight the different skills of potential migrants. 


\section{References}

Autor, D. H. And D. Dorn (2013): "The Growth of Low-Skill Service Jobs and the Polarization of the US Labor Market," American Economic Review, 103, 1553-1597.

Autor, D. H., D. Dorn, And G. H. Hanson (2013): "The China Syndrome: Local Labor Market Effects of Import Competition in the United States," American Economic Review, 103, 2121-2168.

Aydemir, A. (2011): "Immigrant selection and short-term labor market outcomes by visa category," Journal of Population Economics, 24, 451-475.

Aydemir, A. And M. Skuterud (2005): "Explaining the deteriorating entry earnings of Canada's immigrant cohorts, 1966-2000," Canadian Journal of Economics, 38, 641-672.

Beine, M., F. Docquier, And H. Rapoport (2007): "Measuring international skilled migration: a new database controlling for age of entry," The World Bank Economic Review, 21, 249-254.

Bertoli, S., V. Dequiedt, And Y. Zenou (2016): "Can selective immigration policies reduce migrants' quality?" Journal of Development Economics, 119, 100-109.

Bertoli, S., J. Fernández-Huertas Moraga, and F. Ortega (2013): "Crossing the border: Self-selection, earnings and individual migration decisions," Journal of Development Economics, 101, 75-91.

BorJas, G. J. (1987): "Self-Selection and the Earnings of Immigrants," American Economic Review, 77, 531-553.

(1999): Heaven's door: Immigration policy and the American economy, Princeton University Press.

- (2014): Immigration economics, Harvard University Press.

- (2017): "The labor supply of undocumented immigrants," Labour Economics, 46, $1-13$. 
Borjas, G. J. And R. M. Friedberg (2009): "Recent trends in the earnings of new immigrants to the United States," Working Paper No. 15406, National Bureau of Economic Research.

Chen, S. H. (2008): "Estimating the variance of wages in the presence of selection and unobserved heterogeneity," The Review of Economics and Statistics, 90, 275-289.

Chiquiar, D. and G. H. Hanson (2005): "International migration, self-selection, and the distribution of wages: Evidence from Mexico and the United States," Journal of Political Economy, 113, 239-281.

Dustmann, C. And J.-S. Görlach (2016): "Estimating immigrant earnings profiles when migrations are temporary," Labour Economics, 41, 1-8.

Fernández-Huertas Moraga, J. (2013): "Understanding different migrant selection patterns in rural and urban Mexico," Journal of Development Economics, 103, 182-201.

Heckman, J. J. And T. Kautz (2012): "Hard evidence on soft skills," Labour Economics, 19, 451-464.

Mattoo, A., I. C. Neagu, And Ç. Özden (2008): "Brain waste? Educated immigrants in the US labor market," Journal of Development Economics, 87, 255-269.

Mayer, T. And S. Zignago (2011): "Notes on CEPII's distances measures: The GeoDist database," CEPII Working Paper No. 2011-25, Paris.

McKenzie, D., S. Stillman, and J. Gibson (2010): "How important is selection? Experimental vs. non-experimental measures of the income gains from migration," Journal of the European Economic Association, 8, 913-945.

Ortega, F. And A. Hsin (2018): "Occupational Barriers and the Labor Market Penalty from Lack of Legal Status," IZA Discussion Paper No. 11680, Institute for the Study of Labor.

TANI, M. (2018): "Selective Immigration, Occupational Licensing, and Labour Market Outcomes of Foreign-Trained Migrants," IZA Discussion Paper No. 11370, Institute for the Study of Labor. 